\title{
Parental vaccine knowledge and behaviours: a survey of Turkish families
}

Soner Sertan Kara, ${ }^{1}$ Meltem Polat, ${ }^{1}$ Burcu Ceylan Yayla, ${ }^{1}$ Tugba Bedir Demirdag, ${ }^{1}$ Anil Tapisiz, ${ }^{1}$ Hasan Tezer ${ }^{1}$ and Aysu Duyan Camurdan ${ }^{2}$

${ }^{1}$ Department of Paediatric Infectious Diseases; ${ }^{2}$ Department of Social Paediatrics, Faculty of Medicine, Gazi University, Ankara, Turkey (Correspondence to: Soner S. Kara: drsoner@yahoo.com).

\begin{abstract}
Background Personal and herd immunity require durability in high vaccination coverage rates, and this mainly depends on the interaction between parental and service/provider factors.

Aims: The aim of this study was to assess Turkish parents' knowledge and behaviours concerning childhood vaccination and their association with familial sociodemographic characteristics.

Methods: A cross-sectional survey, including a questionnaire, was conducted with parents of children aged between 1 day and 120 months.

Results: Of the 903 index children, 881 (97.6\%) were up to date for all vaccinations by age. Demographic variables were not related to belief in protection through vaccination or rejection of obligatory vaccines. Mean age, education level, occupation of mother $(P=0.006, P<0.001$, and $P=0.01$, respectively) and father $(P=0.002, P<0.001$, and $P=0.006$, respectively), average monthly household income $(P<0.001)$, and experience of vaccine side-effects $(P=0.02)$ were associated with knowledge about optional childhood vaccines. Father's education level was independently associated with knowledge about optional childhood vaccines.
\end{abstract}

Conclusions: Having any experience of vaccine side-effects and parental sociodemographic characteristics, especially father's education level, affect Turkish parents' knowledge of childhood optional vaccines.

Keywords: Childhood, vaccine, immunization, parental knowledge, Turkey

Citation: Kara SS; Polat M; Cura Yayla B; Bedir Demirdag T; Tapisiz A; Tezer H; et al. Parental vacccine knowledge and behaviours: a survey of Turkish families. East Mediterr Health J. 2018;24(5):451-458. https://doi.org/10.26719/2018.24.5.451

Received: 07/04/16; accepted: 15/05/17

Copyright (c) World Health Organization (WHO) 2018. Some rights reserved. This work is available under the CC BY-NC-SA 3.0 IGO license (https:// creativecommons.org/licenses/by-nc-sa/3.o/igo).

\section{Introduction}

Vaccination is one of the main preventive measures in national public health policies. Over the last few decades, newer vaccines have been rapidly added to the Turkish national immunization programme and are provided free and without obligation by the Ministry of Health (1). Except for optional vaccines [rotavirus, meningococcal, human papillomavirus (HPV), and influenza virus], the Turkish national immunization programme offers vaccines that protect against most of the vaccinepreventable diseases typically addressed by equivalent programmes in developed countries $(2,3)$.

According to Ministry of Health data, very high vaccination coverage rates of $96-97 \%$ were reported for the vaccines in the national immunization programme in 2012 [for diphtheria, tetanus, acellular pertussis vaccines (DTaP)-1-2-3, measles, mumps, rubella (MMR), 7-valent pneumococcal conjugate vaccine $\left(\mathrm{PCV}_{7}\right)$ and hepatitis B (HBV)-1-2-3] (4), enough to achieve herd immunity for these diseases, and thus protect even unvaccinated children.

Recommending optional vaccines is considered an integral part of the health services provided in paediatric clinics. While ensuring that all babies are up to date with their compulsory immunizations, counselling can give parents the choice of accepting one or more optional vaccines (5). The coverage for optional vaccines may vary in different populations for various reasons, such as low awareness and the perceived costs of obtaining these vaccines (6).

Turkey's geographical position, its close proximity to countries in a state of war and with low vaccination coverage, and receiving extensive immigration always raises the possibility of a reintroduction of formerly eradicated vaccine-preventable diseases such as polio (7). In addition to these epidemiological risks, parents' negative perceptions and attitudes and lack of knowledge regarding immunization may gradually lower the high vaccination rates achieved so far. In different populations, under-vaccination has been shown to be related to inadequate immunization services and parental knowledge, attitudes and concerns $(8,9)$.

In order to sustain high vaccination coverage rates and to maintain positive family attitudes towards vaccination, vaccination interventions must be targeted on the basis of areas of interest, such as parents' knowledge, attitudes and beliefs or levels of hesitancy, in addition to how parents assess vaccination (10).

The aim of this study was to assess the current knowledge and behaviours of Turkish parents concerning childhood vaccines and vaccination, and 
to demonstrate the associations between vaccination status, belief in the protective effects of vaccination, parental thinking regarding rejected childhood vaccines, knowledge concerning childhood optional vaccines and sociodemographic characteristics.

\section{Methods}

This cross-sectional survey of a non-randomized sample of 903 parents (57\% of 1560 eligible parents) was carried out at paediatric outpatient clinics (paediatrics, paediatric infectious diseases, and well-child care) in Gazi University Hospital between 1 January and 31 December 2014. Data for the study were based on interviews with parents of index children aged between 1 day and 120 months at the time of the study, and who consented to participate while attending for various medical reasons. The interviews were conducted by 2 specialists in paediatric infectious diseases, who also explained the medical terms involved. The vaccination status of the index children was determined by checking written vaccination records or on the basis of parental declarations if no such a card was available, and this was later compared with the digital records of the hospital.

The study questionnaire included open and closed questions. Some items in the survey were drafted by modifying similar, previously published surveys (11-14). In addition to general demographic variables (age and sex of index children; age, level of education and occupation of both parents; average monthly household income) and underlying disease of index children, the questionnaire also enquired into parents' knowledge and behaviours concerning vaccines (whether vaccines were thought to be protective, whether any vaccines in the national immunization programme were unacceptable, whether the optional vaccines were known, which optional vaccines had been administered, whether any adverse reactions related to vaccines had been experienced, and from which person/setting the caregivers first seek assistance in the event of adverse reactions during vaccination).

In order to assess belief in the protective effects of vaccination, caregivers were asked if they thought the vaccines were protective or not, and their answers were scored on a 5-point Likert-type scale. Answers ranged from "yes, certainly" to "no, certainly not".

In order to assess attitudes to routine vaccines, caregivers were asked whether there were any unacceptable vaccines for their child in the national immunization programme. Answers on a 5-point Likerttype scale ranged from "There is no routine vaccine that I refuse to use for my child(ren)" to "I refuse to vaccinate my child(ren) with any of the routine vaccines". In order to assess knowledge of optional vaccines, caregivers were asked whether there were any optional vaccines not included in the national immunization programme that they could pay for and have their children vaccinated with. Answers ranged from "Yes, I certainly agree" to "No, I certainly do not agree" on a 5-point Likert-type scale.
Children's vaccination status was defined as completely immunized if they had been immunized up to age and partially immunized if they had missed at least 1 of the vaccines in the programme. Children in our study who had not received either hepatitis A or varicellazoster vaccines were nonetheless regarded as completely immunized because the majority of the children were older than the recommended age for these vaccines.

Verbal informed consent was obtained from all parents. Approval was granted for the study from the Institutional Ethical Committee of the Faculty of Medicine, Gazi University. The patient's identity and other personal information were kept confidential at data analysis by using unique codes for each patient.

Data were analysed using SPSS, version 16.0. The Kolmogorov-Smirnov test was used to verify that continuous variables were normally distributed. Continuous variables were expressed as mean and standard deviation (SD) or median (minimummaximum), and categorical variables were expressed as percentages. The independent samples t-test was used for continuous variables and the chi-squared test for categorical variables. Those variables identified as significant for possession of knowledge of optional childhood vaccines at univariate analysis (sex of child and parent, education level of mother and father, and presence of any experience of vaccine side-effects) were included in binary logistic regression analysis in order to explore independent associations with knowledge of these vaccines (the answers to the parental knowledge of optional childhood vaccines on the 5-point Likert-type scale were grouped into 2 in this analysis: "yes, I certainly agree" and "yes I agree" were included in 1 group and the rest were included in the other group). Statistical significance was set at $P<0.05$.

\section{Results}

\section{Participants}

We surveyed 903 parents for this study. Most were from the Paediatric Infectious Diseases clinic $(n=567,62.8 \%)$ and were mothers $(n=651,72.1 \%)$.

\section{Personal characteristics of the children investigated}

Characteristics of the index children and parents are shown in Table 1 . The median age was 36 months (range 6 days to 120 months). There were 470 male children (52.0\%) and 433 females (48.0\%), a male to female ratio of 1.08 . We found that 135 children (14.9\%) had a chronic disease, the most common being immunodeficiency ( $n$ $=23,2.5 \%$ ). Most of the caregivers involved in the child's vaccination were mothers $(n=507,56.1 \%)$. The mean ages of mothers and fathers was 32.2 (SD 6.2) and 35.7 (SD 6.4) years, respectively. The majority of mothers and fathers had graduated from secondary or high school ( $n=450$, $49.8 \%$ and $n=477,52.8 \%$, respectively). Average monthly household incomes mostly fell into the highest category (> $4000 \mathrm{TL} / \mathrm{month})(n=274,30.3 \%)$. Nearly half $(54.2 \%)$ of the families had average monthly incomes above the rural poverty threshold, while $30.3 \%$ were over the 
poverty threshold for whole of Turkey determined by the Turkish Statistical Institute (15).

\begin{tabular}{|c|c|c|}
\hline Characteristic & No. & $\%$ \\
\hline Median age of children (months) (range) & $36(0.2-120)$ & \\
\hline \multicolumn{3}{|l|}{ Sex of index child } \\
\hline Male & 470 & 52.0 \\
\hline Female & 433 & 48.0 \\
\hline \multicolumn{3}{|c|}{ Principal caregiver involved in child's vaccination } \\
\hline Mother & 507 & 56.1 \\
\hline Father & 17 & 1.9 \\
\hline Mother \& father & 372 & 41.2 \\
\hline Other (grandmother, uncle, etc.) & 7 & 0.8 \\
\hline \multicolumn{3}{|l|}{ Maternal education level } \\
\hline Elementary school & 84 & 9.3 \\
\hline Secondary/high school & 450 & 49.8 \\
\hline University & 369 & 40.9 \\
\hline \multicolumn{3}{|l|}{ Maternal occupation } \\
\hline Housewife & 558 & 61.8 \\
\hline Public official & 260 & 28.7 \\
\hline Self employed & 41 & 4.5 \\
\hline Doctor/nurse & 44 & 4.8 \\
\hline \multicolumn{3}{|l|}{ Paternal education level } \\
\hline Elementary school & 71 & 7.8 \\
\hline Secondary/high school & 477 & 52.8 \\
\hline University & 355 & $39 \cdot 3$ \\
\hline \multicolumn{3}{|l|}{ Paternal occupation } \\
\hline Manual & 245 & 27.1 \\
\hline Public official & 349 & 38.6 \\
\hline Self employed & 297 & 32.8 \\
\hline Doctor & 12 & 1.3 \\
\hline \multicolumn{3}{|l|}{ Average monthly household income $(\mathrm{TL})^{\alpha}$} \\
\hline$<1000$ & 171 & 18.9 \\
\hline $1000-3000$ & 242 & 26.8 \\
\hline $3001-4000$ & 216 & 23.9 \\
\hline$>4000$ & 274 & 30.3 \\
\hline \multicolumn{3}{|l|}{ Immunization status of index children } \\
\hline Completely immunized & 881 & 97.5 \\
\hline Partially immunized & 22 & 2.4 \\
\hline Unimmunized & 0 & 0 \\
\hline \multicolumn{3}{|l|}{ Underlying diseases of the index children } \\
\hline Immunodeficiency & 23 & 2.5 \\
\hline Chronic heart disease & 8 & 0.9 \\
\hline Chronic lung disease & 17 & 1.9 \\
\hline Renal disease & 10 & 1.1 \\
\hline Diabetes mellitus & 3 & 0.3 \\
\hline Other $^{\mathrm{b}}$ & 74 & 8.2 \\
\hline None & 768 & 85.0 \\
\hline
\end{tabular}

${ }^{a_{1}}$ US\$ $\cong 2.6$ Turkish lira (TL).

${ }^{5}$ Includes congenital metabolic/neurometabolic disorders, other endocrinopathies, neurological disorders, etc.
There were no unvaccinated children, but $22(2.4 \%)$ were only partially immunized. Reasons cited for partial immunization were wishing the child to acquire immunity through natural infections $(n=8,36.3 \%)$, lack of interest $(n=6,27.2 \%$ ), thinking that vaccination causes serious side-effects $(n=4,18.1 \%)$, believing vaccination to be useless $(n=3,13.6 \%)$, and thinking that vaccination causes illness $(n=1,4.5 \%)$. No statistically significant association was observed between the immunization status of the index children and the characteristics of the study population (age of the index children and their parents, gender and underlying diseases of the index children, education level and occupation of both parents, and average monthly household income of the family).

\section{Knowledge and beliefs of parents regarding childhood vaccines and vaccination}

Most parents $(n=859,95.1 \%)$ reported believing in the protective effects of vaccination. No statistically significant association was determined between belief in vaccination's protective effects and the characteristics of the study population $(P>0.05)$.

In our study population, $2.7 \%(n=25)$ of parents considered one or more vaccines in the childhood national immunization programme unacceptable. Levels of rejection of hepatitis B $(n=13,52.0 \%)$, Bacillus Calmette-Guérin vaccine (BCG) $(n=10,40.0 \%)$, hepatitis A ( $n=10,40.0 \%)$, diphtheria, tetanus, acellular pertussis, inactivated polio, Haemophilus influenza type $B$ vaccine (DTaP-IPV-Hib) $(n=10,40.0 \%)$, MMR $(n=9,36.0 \%)$, varicella $(n=8,32.0 \%)$, and oral polio vaccine (OPV) $(n=$ $7,28.0 \%$ were all similar. No association was determined between the characteristics of the study population and parental thinking regarding unacceptable childhood vaccine $(s)(P>0.05)$.

Two-thirds of parents $(n=602,66.6 \%)$ knew about optional vaccines. Of these, $33.4 \%(n=302)$ had their children inoculated with optional vaccines. Influenza ( $n$ $=97,32.1 \%)$ and rotavirus $(n=94,31.1 \%)$ were the mostly popular and implemented vaccines. Three hundred one $(33.3 \%)$ parents were completely uninformed about optional vaccines, and $78.7 \%(n=237)$ of these felt that health-care professionals, especially doctors, should have informed them about optional vaccines. The relationship between the characteristics of the study population and parental knowledge of the optional vaccines is shown in Table 2. While the median age of the index children was not associated with knowledge of optional childhood vaccine(s), the mean ages of the mothers and fathers were statistically significantly correlated with such knowledge ( $P=0.006$ and $P=0.002$, respectively). Parents' education level, occupation of mothers and fathers, average monthly household income and any experience of vaccine sideeffects were also statistically significantly correlated with knowledge of optional childhood vaccines (Table 2).

Regression analysis showed that the father's education level was independently associated with knowledge of optional childhood vaccines (Table 3). Fathers who had graduated from secondary/high school had a 1.8-fold 


\begin{tabular}{|c|c|c|c|c|c|}
\hline \multirow[t]{2}{*}{ Characteristic } & \multicolumn{4}{|c|}{ Optional childhood vaccines known } & \multirow[b]{2}{*}{ P-value } \\
\hline & \multicolumn{2}{|c|}{ Yes } & \multicolumn{2}{|c|}{ No } & \\
\hline Median age of index children (years) mean (SD) & $3.5(2.8)$ & & $3.4(3.0)$ & & 0.81 \\
\hline Mean (SD) age of fathers & $36.2(6.3)$ & & $34.8(6.5)$ & & $0.002^{*}$ \\
\hline \multirow[t]{2}{*}{ Mean (SD) age of mother } & $32.6(6.1)$ & & $31.4(6.4)$ & & $0.006^{*}$ \\
\hline & No. & $\%$ & No. & $\%$ & \\
\hline Male sex in index children & 310 & 66.0 & 160 & 34.0 & 0.63 \\
\hline Chronic diseases in children & & & & & 0.84 \\
\hline Present & 89 & 14.8 & 46 & 15.2 & \\
\hline Not present & 513 & 85.2 & 255 & 84.7 & \\
\hline Education level of mother & & & & & $<0.001^{*}$ \\
\hline Elementary school & 2 & 0.3 & 2 & 0.6 & \\
\hline Secondary/high school & 314 & 52.1 & 216 & 71.7 & \\
\hline University & 286 & 47.5 & 83 & 27.5 & \\
\hline Occupation of mother & & & & & $0.01^{*}$ \\
\hline Housewife & 346 & 57.4 & 212 & 70.4 & \\
\hline Government official & 196 & 32.5 & 64 & 21.2 & \\
\hline Self-employed & 26 & 4.3 & 15 & 4.9 & \\
\hline Doctor/nurse & 34 & 5.6 & 10 & 3.3 & \\
\hline Education level of father & & & & & $<0.001^{*}$ \\
\hline Elementary school & 1 & 0.1 & 1 & 0.2 & \\
\hline Secondary/high school & 316 & 52.4 & 230 & 76.4 & \\
\hline University & 285 & 47.3 & 70 & 23.2 & \\
\hline Occupation of father & & & & & $0.006^{*}$ \\
\hline Manual & 143 & 23.7 & 102 & 33.8 & \\
\hline Public official & 249 & 41.3 & 100 & 33.2 & \\
\hline Self employed & 200 & 33.2 & 97 & 32.2 & \\
\hline Doctor & 10 & 1.6 & 2 & 0.6 & \\
\hline Average monthly household income (TL) ${ }^{a}$ & & & & & $<0.001^{*}$ \\
\hline$<1000$ & 85 & 14.1 & 86 & 28.5 & \\
\hline $1000-3000$ & 161 & 26.7 & 81 & 26.9 & \\
\hline $3001-4000$ & 137 & 22.7 & 79 & 26.2 & \\
\hline$>4000$ & 219 & 36.3 & 55 & 18.2 & \\
\hline Rejection of any childhood vaccine & & & & & 0.77 \\
\hline Yes & 16 & 64.0 & 9 & 36.0 & \\
\hline No & 586 & 66.7 & 292 & 33.3 & \\
\hline Experience of vaccine side-effects & & & & & $0.02^{*}$ \\
\hline Present & 550 & 91.3 & 261 & 86.7 & \\
\hline Not present & 52 & 8.6 & 40 & 13.2 & \\
\hline
\end{tabular}

$S D=$ standard deviation

${ }^{a} 1$ US\$ $\cong 2.6$ Turkish liras (TL).

*Statistically significant $(P<0.05)$.

Table 3. Regression analysis of associations between population characteristics and parental knowledge of optional childhood vaccines

\begin{tabular}{llll}
$\begin{array}{l}\text { Independent } \\
\text { parameter }\end{array}$ & Odds ratio & $\begin{array}{l}\mathbf{9 5 \%} \text { confidence } \\
\text { interval }\end{array}$ & $\mathbf{P}$ \\
\hline $\begin{array}{l}\text { Education level of fathers } \\
\text { Elementary school }\end{array}$ & Reference & & 0.03 \\
Secondary/high school & 1.8 & $1.050-3.138$ & \\
University & 4.1 & $2.185-7.809$ & \\
\hline
\end{tabular}

greater knowledge of optional childhood vaccines and university graduate fathers a 4.1-fold greater knowledge compared to fathers who had graduated from elementary school.

\section{Adverse events and medical information}

Adverse events caused by any vaccine were reported by $811(89.8 \%)$ parents. The most common adverse event was fever ( $n=670 ; 74.1 \%$ ), followed by local reactions ( $n=$ $456,50.4 \%$ ) and irritability $n=257 ; 28.4 \%$ ). The first place 
where caregivers sought information about vaccinations and adverse reactions when these occurred during vaccination were the paediatrician ( $n=456,50.4 \%$ ), followed by the family physician $(n=296,32.7 \%)$, the nurse who administered the vaccine $(n=112,12.4 \%)$, the internet ( $n=21,2.3 \%$ ), and finally parents of other children who may have experienced similar side-effects $(n=3,0.3 \%)$.

\section{Discussion}

This study represents an evaluation of Turkish parental beliefs, knowledge, attitude, and behaviours toward childhood vaccines and vaccination. The study population exhibited a slightly higher percentage of immunization than the Turkish national data reported by the Ministry of Health for each vaccine (4). This may be associated with the city, Ankara, where the study was performed. Ankara is the capital of Turkey, and health care services are more available and caregivers' education levels are higher than the average national values. The parents in the study population were generally young adults, and most were educated to secondary/high school level or above. Occupation of both parents, and older parental age, education level and family income were associated with parental knowledge of optional vaccines. We believe that a certain level of economic status and knowledge and understanding of vaccines and their benefits are important if a vaccine involving additional costs is to attract the interest of parents. Data concerning optional vaccines are scarce in the Turkish-language literature, and the results of this study are particularly significant from that perspective. Logistic regression analysis showed that levels of paternal knowledge of optional vaccines increased in line with education level. However, that association did not apply to mothers. In Turkey it is mostly mothers who are responsible for child care. Similarly, among the caregivers in this study it was predominantly mothers who were involved in the children's vaccinations. Strikingly, however, fathers still desired to receive information about vaccination. This may be attributed to the sociocultural structure in Turkey, which may impact on vaccination coverage because of fathers' roles in decision-making on behalf of all family members. Previous experience with any vaccine side-effects was also associated with knowledge concerning optional childhood vaccines. It is likely that such experience may have resulted in hypervigilance on the part of caregivers, so they were anxious to learn more about the subject.

Influenza and rotavirus vaccines were the most frequently administered optional vaccines in this study. Although no nationwide data are available, similar coverage rates to those in our study have been reported in previous research. Gunduz et al. (16) reported levels of $8.8 \%$ for influenza and $37 \%$ for rotavirus vaccinations among a Turkish study population. Camurdan et al. reported an influenza vaccination rate of 50\% among diabetic children (17). In a 2014 study from Hong Kong, which has immunization coverage rates for mandated vaccines similar to those in Turkey, the coverage rate for seasonal influenza vaccine was $15 \%$, lower than in our study (3). In the present study, parents with no knowledge about optional vaccines felt that health care professionals should have informed them. Similarly, Bardenheier et al. reported that not having received a doctor's or health department recommendation for the Hep A vaccine was cited as the factor most strongly associated with not receiving that vaccination (18). In a previous Turkish study (16), parents of children who did not receive the influenza vaccine tended to believe that vaccination was not essential, rather than citing a lack of recommendation.

Most of the index children (97.6\%) in this study were up-to-date for all vaccinations. Only $2.7 \%$ of the respondents declared an unwillingness to vaccinate their children with one or more of the routine vaccines in the national immunization programme. These low percentages made it impossible to determine statistically significant associations with familial sociodemographic characteristics. In contrast, nearly $12 \%$ of American parents have been reported to refuse at least one recommended childhood vaccine (14). The American Academy of Pediatrics advises physicians to respond to vaccine refusal by respectfully listening to parents' concerns and discussing the risks associated with nonvaccination (19). For partially immunized children, although routine vaccines are provided free of charge by the government, other costs such as transportation may account for children not being up-to-date for all vaccinations. Parental uncertainty regarding the importance of immunization may have resulted in undervaccination, and such anxiety also needs to be alleviated with adequate information (20). Providing better information for parents (9), mass immunization campaigns and proper vaccine delivery systems all play an important role in vaccination uptake in other countries (21). Parents may prefer diseaseinduced immunity to vaccination (22). In our study, no specific vaccine was the subject of particular reluctance, while some vaccines, e.g. measles, HBV and influenza, have been unpopular owing to safety concerns in some parts of the world $(23,24)$.

Most of the index children in this study were healthy. No association was determined with immunization status. Excepting cases of valid medical contraindications for immunization, as well as children who are too young to be vaccinated or whose vaccinations could not reach adequate efficacy and effectiveness, unvaccinated children are not only more prone to vaccine-preventable diseases but may also transmit these diseases to other individuals (13). Children with chronic diseases therefore need to be carefully evaluated in terms of vaccination.

The parents in this study generally agreed that vaccines protected their children against vaccine-preventable diseases; nevertheless, family sociodemographic characteristics were not associated with the decision to vaccinate. Gust et al. observed that their study population generally believed in the protective effect of vaccines, but parents in the lowest income category and parents with lower levels of education exhibited a significantly lower 
level of belief in the protective value of vaccines than parents in other categories (12). Characteristics such as parental age, education and family income have been associated with belief in the protective properties of vaccination in other studies $(19,20,22,23,25,26)$.

A history of vaccine-related adverse events was reported by almost $90 \%$ of parents. Such events may be expected to occur more frequently as vaccination coverage levels increase (12). An increased frequency of vaccine-related adverse events may result in the global perception that vaccines are hazardous, despite continued improvements in vaccine safety (11). Incorrect information given by, or a mistrust of, health professionals may lead to refusal of immunization (27). Nevertheless, paediatricians and family physicians were reported to be the most trusted sources of information regarding vaccines and vaccinations in this study. Unfriendly or disrespectful attitudes and behaviour toward mothers on the part of health workers in developing countries have frequently been cited as discouraging the vaccination of children (8). Physicians are a most important source of reliable information regarding vaccines and vaccination, and good communication with concerned parents to provide them with the information required is therefore particularly important (28). Some populations may place greater trust in other individuals or systems than in health care professionals (29). Some people obtain information from other sources such as family, friends and the internet (11), which may result in the dissemination of uncontrolled information without editorial control or peer review (12). Our study population reported resorting less to the media and internet for information, in agreement with Serpell et al. (9).
The findings of this study should be interpreted in the light of a number of limitations. The findings may not represent all Turkish parents: this was a crosssectional study and the study population was sampled from health clinics. The study population therefore consisted of caregivers who were least able to travel to a hospital. The study was not designed to evaluate the reason(s) for partial immunization, or which measures might be taken to resolve problems identified in it. It also did not evaluate the presence of any underlying parental disease, the characteristics of siblings or parental attitude towards combination vaccines, all of which may influence parental decisions, perceptions and attitudes concerning vaccination. The age range of the children was also very wide. This may have resulted in inconsistencies in recalling vaccine-related experiences, especially among the parents of older children. Additionally, nonsignificant associations were determined between children's immunization status, parents' beliefs in the protective effects of vaccinations and the demographic characteristics of the study population due to the disproportional distribution of the groups. A larger study population and a multicentre design may have elicited more homogeneous population characteristics.

In conclusion, this study may represent a useful source of information concerning Turkish parental beliefs, knowledge, attitudes and behaviours toward childhood vaccination. Vaccination coverage in this study was similar to national levels, although some important demographic variables differed somewhat from national averages. Parents' sociodemographic characteristics, and particularly paternal education level, were shown to affect knowledge of optional vaccines in the Turkish population.

\section{Funding: None.}

Competing interests: None declared.

\section{Connaissance parentale des vaccins et comportements à cet égard : étude de familles turques}

\section{Résumé}

Contexte : L'établissement d'une immunité personnelle et collective nécessite que les taux de couverture vaccinale demeurent durablement élevés, ce qui dépend grandement de l'interaction entre les parents et les services/prestataires de vaccination.

Objectifs : La présente étude avait pour objectif d'évaluer les connaissances et les comportements des parents turcs en termes de vaccination durant l'enfance, ainsi que leur association avec les caractéristiques socio-démographiques familiales.

Méthodes : Une étude transversale, incluant un questionnaire, a été menée auprès des parents d'enfants dont l'âge était compris entre 1 jour et 120 mois.

Résultats : Sur les 903 enfants index, 881 (97,6\%) étaient à jour pour toutes les vaccinations par groupe d'âge. Les variables démographiques n'étaient pas liées au fait de croire à une protection induite par la vaccination ou à un rejet des vaccins obligatoires. L'âge moyen, le niveau d'éducation, la profession de la mère $(p=0,006, p<0,001$, et $p=0,01$, respectivement) et du père ( $p=0,002, p<0,001$, et $p=0,006$, respectivement), le revenu mensuel moyen du foyer ( $p$ $<0,001)$, et des antécédents d'effets secondaires des vaccins $(p=0,02)$ étaient associés à une connaissance des vaccins facultatifs pour les enfants. Le niveau d'éducation du père avait une association indépendante avec la connaissance des vaccins facultatifs pour les enfants. 
Conclusions : Les antécédents d'effets secondaires liés aux vaccins ainsi que les caractéristiques socio-démographiques parentales, notamment le niveau d'éducation du père, influencent les connaissances des parents turcs en termes de vaccins facultatifs pour les enfants.

$$
\text { معلومات أولياء الأمور بالتطعيمات وسلو كياتهم تجاهها: دراسة استقصائية للأسر التركية }
$$

الخلفية: تستلزم المناعة الشخصية ومناعة القطيع استمرارية الحفاظ على معدلات تغطية مرتفعة للتطعيات، وهو ما يعتمد أساساً على التفاعل بين أولياء الأمور ومقدمي الخدمة.

الأهداف: هدفت هذه الدراسة إلى تقييم معلومات أولياء الأمور الأتراك وسلوكياتهم إزاء تطعيم الأطفال وارتباط ذلك بالسمات الاجتماعية السكانية للأسرة.

$$
\text { طرق البحث: أجري مسح مقطعي شمل إجراء استبيان، لأولياء أمور أطفال تتراوح أعمارهم بين يوم واحد و • r الشهراً. }
$$

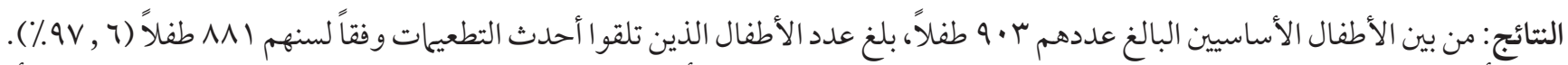

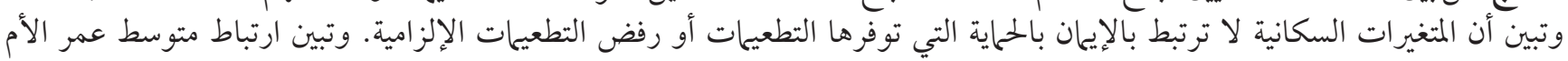

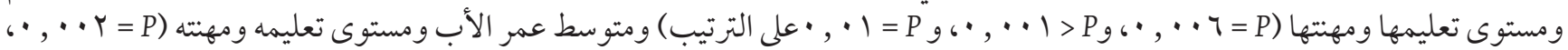

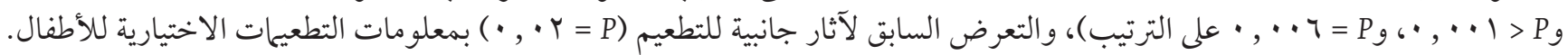

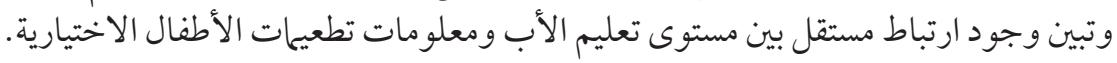

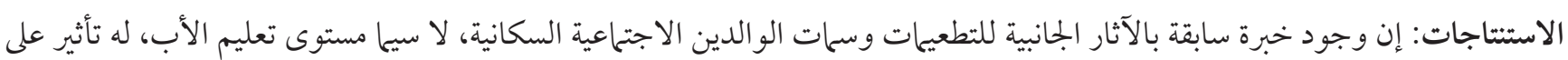

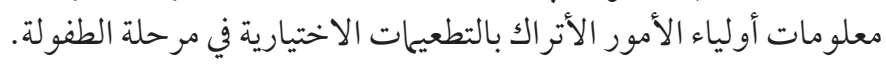

\section{References}

1. Arisoy ES, Ceyhan M, Ciftci E, Hacimustafaoglu M, Kara A, Kuyucu N, et al. The national vaccination schedule in previously healthy children: the practical recommendations about additional vaccines. Çocuk Enfeksiyon Dergisi [J Pediatr Inf]. 2014;8:1-6.

2. Recommended immunization schedule for persons aged o through 18 years - United States. Atlanta: Centers for Disease Control and Prevention; 2015 (https://www.cdc.gov/vaccines/schedules/downloads/past/2015-child.pdf, accessed 01 December 2015).

3. Wang LD, Lam WW, Wu JT, Liao Q, Fielding R. Chinese immigrant parents' vaccination decision making for children: a qualitative analysis. BMC Public Health. 2014;14:133. PMID:24507384

4. Turkish Ministry Health Annual of health statistics. Ankara: General Directorate of Health Research; 2013 (in Turkish).

5. Kannan Kutty P, Pathmanathan G, Salleh NM. Analysis of factors in response to rotavirus vaccination counselling in a private paediatric clinic. Med J Malaysia. 2010;65(2):127-32. PMID:23756797

6. Manthiram K, Blood EA, Kuppuswamy V, Martins Y, Narayan A, Burmeister K, et al. Predictors of optional immunization uptake in an urbansouth Indian population. Vaccine. 2014;32(27):3417-23. PMID: 24736005

7. Vancelik S, Guraksin A, Ayyildiz A, Beyhun NE. Seroepidemiology of poliovirus antibody among the children in Eastern Turkey. Indian J Med Res. 2007;126(6):528-33. PMID:18219079

8. Favin M, Steinglass R, Fields R, Banerjee K, Sawhney M. Why children are not vaccinated: a review of the grey literature. Int Health. 2012;4(4):229-38. PMID:24029668

9. Serpell L, Green J. Parental decision-making in childhood vaccination. Vaccine. 2006;24(19):4041-6. PMID:16530892

10. Brunson EK. How parents make decisions about their children's vaccinations. Vaccine. 2013;31(46):5466-70. PMID:24076175

11. Downs JS, de Bruin WB, Fischhoff B. Parents' vaccination comprehension and decisions. Vaccine. 2008;26(12):1595-607. PMID:18295940

12. Gust DA, Woodruff R, Kennedy A, Brown C, Sheedy K, Hibbs B. Parental perceptions surrounding risks and benefits of immunization. Semin Pediatr Infect Dis. 2003;14(3):207-12. PMID:12913833

13. Kennedy AM, Brown CJ, Gust DA. Vaccine beliefs of parents who oppose compulsory vaccination. Public Health Rep. 2005;120(3):252-8. PMID:16134564

14. Opel DJ, Taylor JA, Mangione-Smith R, Solomon C, Zhao C, Catz S, et al. Validity and reliability of a survey to identify vaccinehesitant parents. Vaccine. 2011;29(38):6598-605. PMID:21763384

15. Income distribution and Living Conditions Statistics 2011. Ankara: Turkish Statistical Institute; 2014 (TUIK website) (http://www. tuik.gov.tr/PreHaberBultenleri.do?id=16083, accessed 05 November 2015) [in Turkish].

16. Gunduz S, Yuksel NC, Aktoprak HB, Canbal M, Kaya M. Attitudes towards influenza vaccination in high socioeconomic status Turkish parents. Turk J Med Sci. 2014;44(4):649-55. PMID: 25551937 
17. Camurdan MO, Camurdan AD, Beyazova U, Bideci A. The rate of seasonal influenza vaccination in diabetic children, the effect of recommendation and the factors influencing the acceptance of recommendation: an interventional study. Balkan Med J. 2012;29(4):434-9. PMID: 25207049

18. Bardenheier B, González IM, Washington ML, Bell BP, Averhoff F, Massoudi MS, et al. Parental knowledge, attitudes, and practices associated with not receiving hepatitis A vaccine in a demonstration project in Butte County, California. Pediatrics. 2003;112(4):e269. PMID: 14523210

19. Diekma DS; American Academy of Pediatrics Committee on Bioethics. Responding to parental refusals of immunization of children. Pediatrics. 2005;115(5):1428-31. PMID: 15867060

20. Tickner S, Leman PJ, Woodcock A. Factors underlying suboptimal childhood immunisation. Vaccine. 2006;24(49-50):7030-6. PMID:16890330

21. Barreto TV, Rodrigues LC. Factors influencing childhood immunisation in an urban area of Brazil. J Epidemiol Community Health. 1992;46(4):357-61. PMID:1431706

22. Streefland PH. Public doubts about vaccination safety and resistance against vaccination. Health Policy. 2001;55(3):159-72. PMID:11164965

23. Alfredsson R, Svensson E, Trollfors B, Borres MP. Why do parents hesitate to vaccinate their children against measles, mumps and rubella? Acta Paediatr. 2004;93(9):1232-7. PMID:15384890

24. Langer-Gould A, Qian L, Tartof SY, Brara SM, Jacobsen SJ, Beaber BE, et al. Vaccines and the risk of multiple sclerosis and other central nervous system demyelinating diseases. JAMA Neurol. 2014;71(12):1506-13. PMID:25329096

25. Gust DA, Strine TW, Maurice E, Smith P, Yusuf H, Wilkinson M, et al. Underimmunization among children: effects of vaccine safety concerns on immunization status. Pediatrics. 2004;114(1):e16-22. PMID:15231968

26. Smith PJ, Humiston SG, Marcuse EK, Zhao Z, Dorell CG, Howes C, et al. Parental delay or refusal of vaccine doses, childhood vaccination coverage at 24 months of age, and the health belief model. Public Health Rep. 2011;126(Suppl. 2):135-46. PMID:21812176

27. Ołpiński M. Anti-vaccination movement and parental refusals of immunization of children in USA. Pediatriapolska. 2012;87(4):381-5.

28. Taylor JA, Darden PM, Slora E, Hasemeier CM, Asmussen L, Wasserman R. The influence of provider behavior, parental characteristics, and a public policy initiative on the immunization status of children followed by private pediatricians: a study from Pediatric Research in Office Settings. Pediatrics. 1997;99(2):209-15. PMID:9024448

29. Paulussen TG, Hoekstra F, Lanting CI, Buijs GB, Hirasing RA. Determinants of Dutch parents' decisions to vaccinate their child. Vaccine. 2006;24(5):644-51. PMID:16157423 